\title{
eWorkbooks for Mathematics: Mapping the Independent Learning Experiences of Elementary Students with Learning Disabilities
}

\author{
Tara Kaczorowski and Sharon Raimondi \\ University at Buffalo, USA \\ tarakacz@buffalo.edu
}

\begin{abstract}
In this paper, we describe a small case study exploring how four elementary students with mathematics learning disabilities utilized mobile technology (the eWorkbook) during core math instruction in a general education setting. The lead author designed the eWorkbook intervention to provide a flexible learning experience optimized for diverse learners. Sophisticated video-coding software was used to map the actions of the students as they engaged with the tool during the independent practice portion of math instruction. Results related to engagement, independence, accuracy, and specific affordances and barriers to learning with mobile technology are reported.
\end{abstract}

KEYWORDS: Learning disabilities, mathematics, mobile technology, K-12, video coding

\section{INTRODUCTION}

At its core, the goal of learning analytics is to study learners and their contexts to optimize learning environments (Siemens, 2013). Within this emerging field, much of the research and assessment has been focused on learning processes (as opposed to learning outcomes) in online environments of higher education settings where large amounts of data are already collected (Becker, 2013). The lead author of the present study aimed to extend the field of learning analytics by observing the learning contexts of elementary-aged learners of a currently underrepresented population in the learning analytics field: students with learning disabilities (LD).

\section{BACKGROUND}

Students with LD make up approximately $5 \%$ of the school-age population in the United States (Cortiella \& Horowitz, 2014). Students with LD specific to the domain of mathematics are known to have deficits in number sense, visuo-spatial representations, working memory, attention, and self-regulatory skills (Geary, 2010), so they often require specialized instruction. Despite this need for specialized instruction, $66 \%$ of students with LD spend $80 \%$ or more of their school day in the general education setting (Cortiella \& Horowitz, 2014). The National Mathematics Advisory Panel (2008) suggests that technology may be a useful way to support these students in this setting; however, relatively little is known about the actual impact of technology on the math achievement of K-12 students. Most of the research on technology use in the classroom either focuses on student perceptions of achievement (Wu et al., 2012) or implements technology separately from core instruction (Slavin \& Lake, 2008). Most of the research 
(2014). eWorkbooks for Mathematics: Mapping the Independent Learning Experiences of Elementary Students with Learning Disabilities. Journal of Learning Analytics, 1 (3), 179-182.

leveraging mobile technology to support the needs of students with disabilities has been used for behavioural or communication purposes (Kagohara et al., 2013). The lead author designed the eWorkbook intervention, an iPad-based interactive, multimedia math workbook, to address the recommendations of the National Mathematics Advisory Panel (2008) and the gap in the research.

\section{METHODOLOGY}

In this qualitative case study, the authors video-recorded four 3rd grade students with LD as they used the eWorkbook during the independent math practice portion of daily math lessons. The lead author designed the eWorkbook, using an Agile approach to tool development (Fowler \& Highsmith, 2001), to replace the paper-pencil math worksheets from the math program. In Agile development, stakeholders and developers work together during the development process to make flexible, working iterations of a product. All eWorkbook iterations contained review videos, interactive practice opportunities, immediate feedback questions, hints, virtual manipulatives, and other multimedia tools for students to practice the skills from the math lesson independently. Video recordings were coded using StudiocodeTM software to map the actions of the students during independent practice. Examples of codes include student attention (e.g., where they were looking), navigational habits (e.g., how quickly they were swiping through pages), independent work habits (e.g., how often they were asking for help), and engagement (e.g., how often they used the tools and supports in the book). A grounded theory approach to data analysis was used to generate the findings (Glaser \& Strauss, 1967).

\section{RESULTS}

Here we offer some broad findings from this exploratory study. In general, the students were more accurate and more independent when they used the eWorkbook than when they used paper-pencil worksheets. The review videos and the immediate feedback practice questions were the most useful supports for arriving at a correct answer, though the students did not always use these tools as intended. When watching review videos, they were often not looking at the video, and rather than trying to solve the practice questions with immediate feedback, they often used a guess-and-check approach. Even though they did not use these supports as intended, they both still led to learning. For example, several students used the immediate feedback questions as model/reference problems to help them with later problems, so they were still helpful. For the review videos, after analyzing student interviews, the lead author discovered that the reason students were not watching the videos at times was because there was no new visual information on the page; they were watching other visual stimuli in the room while listening to the video. Off-task habits in the paper-pencil condition were often on-task in the eWorkbook condition (e.g., when students switched writing utensils in the paper-pencil condition it was for task-avoidance, but in the eWorkbook condition, it was to highlight key features of a problem or to fit their writing on a line). Students were also able to collaborate and support one another while engaging in different tasks when working in the eWorkbook. Additional themes emerged related to the teacher's proximity to the students, classroom climate, expectations of technology, and the design of 
(2014). eWorkbooks for Mathematics: Mapping the Independent Learning Experiences of Elementary Students with Learning Disabilities. Journal of Learning Analytics, 1 (3), 179-182.

the eWorkbook. Many of these themes will be explored in a larger-scale follow-up study.

\section{CONCLUSIONS AND CONTRIBUTIONS TO LEARNIG ANALYTICS}

The field has seen exciting advances in technology over the past few years that allow for the automated coding of student data (e.g., Mu, Stegmann, Mayfield, Rosé, \& Fischer, 2012; Rosé et al., 2008). These developments open new possibilities for a feasible analysis of large samples of students. In the present study, the authors chose to code by hand because of the small number and unique qualities of the participants. Though the coding process may have been easier with technology that automatically tagged student actions, it was actually the cross-analysis of interviews, field notes, and video codes that lead to many of our conclusions. If we want to optimize learning environments for $\mathrm{K}-12$ students, we must consider the needs of all students, including the needs of students with LD. As new ways to collect, measure, and analyze data in K-12 environments are developed and refined in the field of learning analytics, we urge designers and researchers to consider the diverse learners they will undoubtedly encounter. When studying large samples of students, the use of technology as a tool for automated tagging offers insight about the learning processes of students in a much more timely fashion than traditional hand-coding methods; however, as evidenced by the present study, if we only relied on technology to tag and code typical learning behaviours, we might not have a true understanding of how students learn. Just because a student does not engage in typical learning behaviours, does not mean he or she is not learning. Special educators learn about pedagogy by studying the exceptional cases. The field of learning analytics, too, could learn a lot by studying the learners and contexts of exceptional populations.

\section{REFERENCES}

Becker, B. (2013). Learning analytics: Insights into the natural learning behavior of our students. Behavioral \& Social Sciences Librarian, 32(1), 63-67. doi:10.1080/01639269.2013.751804

Cortiella, C., \& Horowitz, S. H. (2014). The state of learning disabilities: Facts, trends and emerging issues. New York: National Center for Learning Disabilities. Retrieved from http://w.Id.org/images/content/files/stateofld2014/2014\%20State\%20of\%20LD\%20FINAL\%20F OR\%20RELEASE.pdf

Fowler, M., \& Highsmith, J. (2001). The agile manifesto. Software Development, 9(8), 28-35.

Geary, D. C. (2010). Mathematical disabilities: Reflections on cognitive, neuropsychological, and genetic components. Learning and Individual Differences, 20(2), 130-133. doi:10.1016/j.lindif.2009.10.008

Glaser, B. G., \& Strauss, A. L. (1967). The discovery of grounded theory: Strategies for qualitative research. New Brunswick, NJ: Aldine Transaction.

Kagohara, D. M., van der Meer, L., Ramdoss, S., O'Reilly, M. F., Lancioni, G. E., Davis, T. N., ... Sigafoos, J. (2013). Using iPods and iPads in teaching programs for individuals with developmental 
(2014). eWorkbooks for Mathematics: Mapping the Independent Learning Experiences of Elementary Students with Learning Disabilities. Journal of Learning Analytics, 1 (3), 179-182.

disabilities: A systematic review. Research in Developmental Disabilities, 34(1), 147-156. doi:10.1016/j.ridd.2012.07.027

Mu, J., Stegmann, K., Mayfield, E., Rosé, C., \& Fischer, F. (2012). The ACODEA framework: Developing segmentation and classification schemes for fully automatic analysis of online discussions. International Journal of Computer-Supported Collaborative Learning, 7(2), 285-305. doi:10.1007/s11412-012-9147-y

National Mathematics Advisory Panel. (2008). Foundations for success: The final report of the national mathematics advisory panel. Washington, DC: U.S. Department of Education.

Rosé, C., Wang, Y.-C., Cui, Y., Arguello, J., Stegmann, K., Weinberger, A., \& Fischer, F. (2008). Analyzing collaborative learning processes automatically: Exploiting the advances of computational linguistics in computer-supported collaborative learning. International Journal of ComputerSupported Collaborative Learning, 3(3), 237-271. doi:10.1007/s11412-007-9034-0

Siemens, G. (2013). Learning analytics: The emergence of a discipline. American Behavioral Scientist, 57(10), 1380-1400. doi:10.1177/0002764213498851

Slavin, R. E., \& Lake, C. (2008). Effective programs in elementary mathematics: A best-evidence synthesis. Review of Educational Research, 78(3), 427-515. doi:10.3102/0034654308317473

Wu, W.-H., Jim Wu, Y.-C., Chen, C.-Y., Kao, H.-Y., Lin, C.-H., \& Huang, S.-H. (2012). Review of trends from mobile learning studies: A meta-analysis. Computers \& Education, 59(2), 817-827.

doi:10.1016/j.compedu.2012.03.0 